\title{
Money and Monetary Policy in Dynamic Stochastic General Equilibrium Models*
}

\author{
Arnab Bhattacharjee ${ }^{\dagger} \quad$ Christoph Thoenissen ${ }^{\ddagger}$
}

October 2005

\begin{abstract}
We compare three methods of motivating money in New Keynesian DSGE Models: Money-in-the-utility function, shopping time and cashin-advance constraint, as well as two ways of modelling monetary policy, interest rate feedback rule and money growth rules. We use impulse response analysis, and a set of econometric measures of the distance between model and data variance-covariance matrices to compare the different models. We find that the models closed by an estimated interest rate feedback rule imply counter-cyclical policy and inflation rates, which is at odds with the data. This problem is robust to the introduction of demand side shocks, but is not a feature of models closed by an estimated money growth rule. Drawing on our econometric analysis, we argue that the cash-in-advance model, closed by a money growth rule, comes closest to the data.
\end{abstract}

JEL Classification: C13, E32, E52.

Keywords: Intertemporal macroeconomics; role of money; monetary policy; model selection; moment matching.

\footnotetext{
${ }^{*}$ We thank Charles Nolan for many useful discussions and valuable comments. The usual disclaimer applies.

†School of Economics and Finance, and CDMA, University of St Andrews, St Andrews, Fife, KY16 9AL. email: ab102@st-andrews.ac.uk

${ }^{\ddagger}$ School of Economics and Finance, and CDMA, University of St Andrews, St Andrews, Fife, KY16 9AL. email: ct30@st-andrews.ac.uk
} 


\section{Introduction}

How should one model money and monetary policy in quantitative analyses of the business cycle? Within the broad paradigm of the The New Neoclassical Synthesis (NNS) (characterized by monopolistic competition, price and wage stickiness and sometimes by endogenous capital accumulation) there are conflicting approaches. Following Woodford (2003), many economists, such as Canzoneri, Cumby and Diba (2004), now do not model money explicitly at all and incorporate an interest rate feedback rule with coefficients estimated using actual data. Others, e.g., Danthine and Kurmann (2004), incorporate estimated money growth processes into their analyses and model the demand for money explicitly (in their case as a cash-in-advance constraint). And there are a number of other variations along these lines which we mention below. However, the literature is not very explicit regarding the differences between modelling monetary policy through an interest rate feedback rule and a money growth rule, or indeed different ways of modelling the role of money in these models.

In this paper, we examine how the business cycle characteristics of the NNS model depend on how we introduce money into the model and on how we model monetary policy. Specifically, we examine three popular ways to model the role of money: (i) By postulating that real money balances enter the representative agent's utility function directly; (ii) by postulating that holding real money balances helps the representative agent minimizes on shopping time, and (iii) by postulating that the representative agents requires previously accumulated real money balances to purchase goods. We also analyze the differences between modelling monetary policy through an interest rate feedback rule compared to a money growth rule.

Comparing across variants of our models in this way raises some issues. How does one carry out such a comparison? Often, researchers 'eyeball' impulse response functions and unconditional second moments. And although that will play a role in what we do, we formalize this comparison. We employ a set of econometric measures to ascertain which of our proposed specifications best matches the business cycle characteristics of the data. In addition, we also use one of our distance measures to help us calibrate our models.

We find that as long as we model monetary policy with an estimated Taylortype interest rate feedback rule, the NNS model will generate, in contrast to the data, counter-cyclical inflation and policy rates, regardless of how we model money. This is a substantial drawback to this way of modelling money as it is often motivated by appeals to 'realism'; that is, the interest rate is the instrument of monetary policy and hence modelling monetary policy in this way is often argued to be a natural choice. Under an estimated money growth rule, however, both inflation and policy rates become pro-cyclical. The magnitude of the correlation is however only correct when the cash-in-advance constraint is combined with a money growth rule. Our econometric methods allow us to rank the models according to their ability to match the variance-covariance-matrix (VCM) of the Hodrick-Prescott filtered model time series with the VCM of Hodrick-Prescott filtered data. Overall, the cash-in-advance model with a money growth rule 
comes closest to the data. Money-in-the-utility and shopping-time models come closer to the data under a money growth rule than under an interest rate rule. As in Canzoneri et al. (2004), we find that adding estimated government spending shocks does not improve the models' ability to match the data. Indeed, our econometric analysis suggest that for most of our models, adding such a shock actually takes the models further away from the data.

The remainder of this paper is structured as follows: Section 2 sets out our basic model and the different approaches to modelling the role of money. Section 3 analyses two alternative ways of closing the models, first using an interest rate feedback rule and second using a money growth rule. Section 4 states our solution method and describes the calibration of the models' deep parameters as well as the productivity, interest rate and money growth shocks. Section 5 compares a set of key second moments generated by the models to those generated by the data. Section 6 analyses impulse responses to monetary and real shocks. In section 7 , we set out our econometric methodology and use these econometric techniques to rank the different models' ability to match data in order to try to ascertain which specification offers the best fit. In section 8, we attempt to improve the models' fit by using the distance measure to inform our calibration choices. Section 9 seeks to ascertain if the model's fit can be improved by adding government spending shocks. Finally, section 10 concludes.

\section{Different ways to model the role of money}

Our starting point is a new Keynesian DSGE model with monopolistic competition and nominal rigidities in the goods and labour markets, along the lines of Erceg, Henderson and Levin (2000), but where firms produce differentiated goods using labour as well as capital services. In this section, we analyze several ways of introducing money into our basic model. We first discuss those aspects of the model that are not affected by the way we model the role of money and that are therefore common to all versions of the basic model analysed in this paper.

\subsection{Representative firm: factor demands}

Firms are monopolistic competitors who produce their distinctive goods according to the following constant returns technology:

$$
Y_{t}(i)=F\left(A_{t}, K_{t}(i), N_{t}(i)\right) \equiv A_{t} K_{t}(i)^{s_{K}} N_{t}(i)^{1-s_{K}} .
$$

$K_{t}(i)$ is the capital stock which is predetermined in period $t$, and $s_{K}<1$. Firms contract labour and capital in economy-wide competitive markets. The optimal demand for capital and labour is given by (2) and (3) respectively

$$
\begin{aligned}
\rho_{t} & =m c_{t} A_{t} \partial F_{t}(i) / \partial K_{t}(i) ; \\
w_{t} & =m c_{t} A_{t} \partial F_{t}(i) / \partial N_{t}(i) .
\end{aligned}
$$


$\rho_{t}$ denotes the economy-wide rental rate for capital and $m c_{t}$ denotes real marginal cost. Equation (4) provides an equation for marginal cost:

$$
m c_{t}=w_{t} h\left[K_{t}(i), N_{t}(i) ; A_{t}, s_{K}\right] .
$$

Capital accumulation is described by

$$
K_{t+1}(i)=(1-\delta) K_{t}(i)+\phi\left(\frac{x_{t}(i)}{K_{t}(i)}\right) K_{t}(i) .
$$

The initial capital stock, $K_{-1}(i)$, is given and assumed equal across all firms. $\phi(\cdot)$ is strictly concave. An alternative formulation, sometimes employed, is $x_{t}=x\left(K_{t+1} / K_{t} ; \delta\right) K_{t}$. These formulations are equivalent since $I(\cdot) \equiv \phi^{-1}(\cdot)$, and hence is strictly convex. In addition to (5) optimal capital accumulation is described by (6) and (7),

$$
\begin{gathered}
\mu_{t}=\lambda_{t} \phi^{\prime}\left(\frac{x_{t}(i)}{K_{t}(i)}\right) \\
\beta E_{t} \mu_{t+1} \rho_{t+1}+\beta E_{t} \lambda_{t+1}\left[(1-\delta)-\phi^{\prime}\left(\frac{x_{t+1}(i)}{K_{t+1}(i)}\right) \frac{x_{t+1}(i)}{K_{t+1}(i)}+\phi^{\prime}\left(\frac{x_{t+1}(i)}{K_{t+1}(i)}\right)\right]=\lambda_{t} .
\end{gathered}
$$

Equation (6) recognizes the utility foregone, $\mu_{t}$ measures the marginal utility of consumption, from investment at date $t$, taking into account the adjustment costs noted above. (7) captures the dynamic properties of this trade-off; a higher capital stock next period, ceteris paribus, enables higher consumption next period, taking into account depreciation between this period and next, and the discounted impact of next period adjustment costs.

At the economy-wide level, we have the following constraint which states that all output is either consumed or invested:

$$
Y_{t}=C_{t}+x_{t}
$$

\subsection{Representative firm: price setting}

In all the variants of the New Keynesian models that we analyze, prices are sticky in a time dependent manner. The firm will reprice in accordance with the framework suggested by Calvo (1983). That is, if the firm reprices in period $t$ it faces the probability $\alpha^{k}$ of having to charge the same price in period $t+k$. The criterion facing a firm presented with the opportunity to reprice is given by

$$
\max \sum_{k=0}^{\infty}(\alpha \beta)^{k} E_{t}\left\{\frac{\mu_{t+k}}{\mu_{t}}\left[\frac{p_{t}(i)}{P_{t+k}}\left(\frac{p_{t}(i)}{P_{t+k}}\right)^{-\theta} Y_{t+k}^{d}-m c_{t+k}\left(\frac{p_{t}(i)}{P_{t+k}}\right)^{-\theta} Y_{t+k}^{d}\right]\right\},
$$

where the terms in marginal utility ensure that the price set is what would have been chosen by any individual in the economy had they been in charge of price-setting. The optimal price is given by

$$
p_{t}^{\prime}(i)=\frac{\theta \sum_{k=0}^{\infty}(\alpha \beta)^{k} E_{t}\left\{\mu_{t+k} m c_{t+k} P_{t+k}^{\theta} Y_{t+k}^{d}\right\}}{\theta-1 \sum_{k=0}^{\infty}(\alpha \beta)^{k} E_{t}\left\{\mu_{t+k} P_{t+k}^{\theta-1} Y_{t+k}^{d}\right\}} .
$$


In the presence of economy-wide factor markets any producer given the chance to reprice will chose this value. As a result the price-level in our models evolves in the following way:

$$
P_{t}=\left[(1-\alpha) p_{t}^{1-\theta}+\alpha P_{t-1}^{1-\theta}\right]^{\frac{1}{1-\theta}}
$$

\subsection{Labour markets}

We follow the work of Erceg et al (2000) by assuming that labour is supplied by 'household unions' acting non-competitively. Household unions combine individual households' labour supply according to:

$$
N_{t}=\left[\int_{0}^{1} N_{t}(i)^{\frac{\theta_{w}-1}{\theta_{w}}} d i\right]^{\frac{\theta_{w}}{\theta_{w}-1}} .
$$

If we denote by $W$ the price index for labour inputs and by $W(i)$ the nominal wage of worker $i$, then total labour demand for household $i$ 's labour is:

$$
N_{t}(i)=\left[\frac{W_{t}(i)}{W_{t}}\right]^{-\theta w} N_{t}
$$

The household union takes into account the labour demand curve when setting wages. Given the monopolistically competitive structure of the labour market, if household unions have the chance to set wages every period, they will set it as a mark-up over the marginal rate of substitution of leisure for consumption. In addition to this monopolistic distortion, we also allow for the partial adjustment of wages using the same Calvo-type contract model as for price setters. This yields the following maximization problem:

$\max \sum_{k=0}^{\infty}\left(\alpha^{w} \beta\right)^{k} E_{t}\left\{\frac{\mu_{t+k}}{\mu_{t}}\left[\frac{W_{t}(i)}{P_{t+k}}\left[\frac{W_{t}(i)}{W_{t+k}}\right]^{-\theta w} N_{t+k}-m r s_{t+k}\left[\frac{W_{t}(i)}{W_{t+k}}\right]^{-\theta w} N_{t+k}\right]\right\}$

where $m r s$ is the marginal rate of substitution of leisure for consumption.

\subsection{Representative agent: Money in the utility function}

There are a large number of agents in the economy who evaluate their utility in accordance with the following utility function:

$$
E_{t}\left\{U\left(C_{t}, \frac{M_{t}}{P_{t}}, N_{t}\right)\right\} \equiv E_{t}\left\{\frac{C_{t}^{1-\sigma}}{1-\sigma}+\frac{\gamma}{1-b}\left(m_{t}\right)^{1-b}-\Psi \frac{N_{t}^{1+\eta}}{1+\eta}\right\}
$$

$E_{t}$ denotes the expectations operator at time $t, \beta$ is the discount factor, $C$ is consumption, $M$ is the nominal money stock, $P$ is the price-level, $m$ is the stock of real money balances, and $N$ is labour supply. 
Consumption is defined over a basket of goods of measure one and indexed by $i$ in the manner of Spence-Dixit-Stiglitz

$$
C_{t}=\left[\int_{0}^{1} c_{t}(i)^{\frac{\theta-1}{\theta}} d i\right]^{\frac{\theta}{\theta-1}},
$$

where the optimal price level is

$$
P_{t}=\left[\int_{0}^{1} p_{t}(i)^{1-\theta} d i\right]^{\frac{1}{1-\theta}} .
$$

The demand for each good is given by

$$
c_{t}^{d}(i)=\left(\frac{p_{t}(i)}{P_{t}}\right)^{-\theta} Y_{t}^{d},
$$

where $Y_{t}^{d}$ denotes aggregate demand. Agents face a time constraint each period (normalized to unity) such that leisure, $L_{t}$, is given by

$$
L_{t}=1-N_{t} .
$$

Agents also face the following flow budget constraint:

$$
C_{t}+E_{t}\left\{Q_{t, t+1} d_{t+1} \frac{P_{t+1}}{P_{t}}\right\}+m_{t}=d_{t}+m_{t-1} \frac{P_{t-1}}{P_{t}}+w_{t} N_{t}+\Pi_{t}+\tau_{t}
$$

Here $d_{t+1}$ denotes the real value at date $t+1$ of the asset portfolio held at the end of period $t . Q_{t, T}$ is the stochastic discount factor between period $t$ and $T$, and

$$
\frac{1}{1+i_{t}}=E_{t}\left\{Q_{t, t+1}\right\}
$$

denotes the nominal interest rate on a risk-less one-period bond. $w_{t}$ denotes the real wage in period $t$, and $\Pi_{t}$ is the real value of income from the corporate sector remitted to the individual (e.g., think of rental income from the capital stock along with a proportionate share in any final profits). In addition to the standard boundary conditions, the necessary conditions for an optimum include:

$$
\begin{gathered}
U_{C_{t}}(.)=\mu_{t} \\
\mu_{t}=\left(1+i_{t}\right) \beta \mathrm{E} \mu_{t+1} \frac{P_{t}}{P_{t+1}} \\
\frac{U_{M_{t}}(.)}{U_{C_{t}}(.)}=\frac{i}{1+i_{t}}
\end{gathered}
$$

where $\mu$ is the Lagrange multiplier associated with both the consumer's and the firm's optimisation problem. 


\subsection{Representative agent: Shopping time model}

In this model we write our utility function, which is not a direct function of real money balances, in terms of leisure, not labour:

$$
E_{t}\left\{U\left(C_{t}, L_{t}\right)\right\} \equiv E_{t}\left\{\frac{C_{t}^{1-\sigma}}{1-\sigma}+\Psi \frac{L_{t}^{1-\eta}}{1-\eta}\right\}
$$

we have the usual flow budget constraint:

$$
C_{t}+E_{t}\left\{Q_{t, t+1} d_{t+1} \frac{P_{t+1}}{P_{t}}\right\}+m_{t}=d_{t}+m_{t-1} \frac{P_{t-1}}{P_{t}}+w_{t} N_{t}+\Pi_{t}+\tau_{t}
$$

in addition to a shopping time constraint:

$$
L_{t}+N_{t}+H\left(C_{t}, m_{t}\right)=1
$$

Shopping time, $H\left(C_{t}, m_{t}\right)$, depends positively on the level of consumption expenditure and negatively on the consumer's holdings of real money balances.

Money becomes useful because it allows the consumer to reduce the amount of time spent shopping.

In addition to the standard boundary conditions, the necessary conditions for an optimum include:

$$
\begin{gathered}
U_{C}(.)=\mu_{t}\left[1+w_{t} H_{C}\left(C_{t}, m_{t}\right)\right] ; \\
-w_{t} H_{m}\left(C_{t}, m_{t}\right)=\frac{i_{t}}{1+i_{t}} ; \\
\mu_{t}=\left(1+i_{t}\right) \beta E_{t} \mu_{t+1} \frac{P_{t}}{P_{t+1}} ; \\
L_{t}+N_{t}+H\left(C_{t}, m_{t}\right)=1 .
\end{gathered}
$$

\subsection{Representative agent: Cash-in-advance constraint}

In this version of our model timing is important. In each period agents must first go to the money market and obtain cash needed for transactions in both the consumption and capital goods markets. When the money market closes the goods markets open. This specification follows Chari and Kehoe (1999).

Agents obtain utility from consumption and disutility from labour:

$$
E_{t}\left\{U\left(C_{t}, N_{t}\right)\right\} \equiv E_{t}\left\{\frac{C_{t}^{1-\sigma}}{1-\sigma}-\Psi \frac{N_{t}^{1+\eta}}{1+\eta}\right\}
$$

and face the usual budget constraint: 


$$
C_{t}+E_{t}\left\{Q_{t, t+1} d_{t+1} \frac{P_{t+1}}{P_{t}}\right\}+m_{t}=d_{t}+m_{t-1} \frac{P_{t-1}}{P_{t}}+w_{t} N_{t}+\Pi_{t}+\tau_{t} .
$$

Now, however, they also a cash-in-advance constraint on consumption and investment.

$$
m_{t}=C_{t}+x_{t},
$$

which reflects our timing convention that goods and money market transactions occur sequentially in the same period.

The necessary conditions for an optimum are:

$$
\begin{gathered}
U_{C_{t}}(.)=\mu_{t}+\varphi_{t} ; \\
\mu_{t}=\left(1+i_{t}\right) \beta E_{t} \mu_{t+1} \frac{P_{t}}{P_{t+1}} ; \\
\varphi_{t}=\mu_{t}\left(\frac{i_{t}}{1+i_{t}}\right) ; \\
m_{t}=C_{t}+x_{t} .
\end{gathered}
$$

Since the cash-in-advance constraint applies to both consumption and investment, the first order conditions of the representative firm are affected in the following way:

$$
\mu_{t}+\varphi_{t}=\lambda_{t} \phi^{\prime}\left(\frac{x_{t}(i)}{K_{t}(i)}\right)
$$

where $\varphi_{t}$ is the Lagrange multiplier on the cash-in-advance-constraint. The remaining equations are unchanged.

\section{Different ways to model monetary policy}

We consider two popular ways of modelling monetary policy. First we consider that monetary policy is modelled in terms of an interest rate feedback rule. The monetary authority sets the nominal interest rate according to current economic conditions. A common example of this specification is the Taylor rule, under which the nominal interest rate reacts to current inflation and the output gap. Specifically, we assume a Taylor rule with an additional interest rate smoothing term. The log-linearized monetary policy reaction function takes the following form:

$$
i_{t}=\phi_{i} i_{t-1}+\phi_{\pi} \pi_{t}+\phi_{\bar{y}}\left(y_{t}-\bar{y}_{t}\right)+\varepsilon_{i, t} .
$$

This approach is followed by inter alia, Canzoneri et al. (2004) and Nolan and Thoenissen (2005). 
An alternative specification, used for example by Danthine and Kurmann (2004), Kollmann (2005) and Wang and Wen (2005) assumes that the monetary authority exogenously sets the growth rate of money, $g_{M}$, such that supply of real money balance evolves according to:

$$
m_{t}=\left(1+g_{M}\right) m_{t-1} \frac{P_{t-1}}{P_{t}} .
$$

The seigniorage from this activity is redistributed in a lump sum fashion to the consumer yielding real money transfers of:

$$
\tau=g_{M} m_{t-1} \frac{P_{t-1}}{P_{t}} .
$$

\section{Solving the models}

We solve the models by taking a log-linear approximation around the deterministic steady state. The stochastic system of linear difference equations is then solved using the solution algorithm of King and Watson (1998, 2002).

\subsection{Calibration}

Our calibration is standard and is described as follows. We assume a discount factor of 0.984 , which yields an annualized steady-state rate of interest of $6.5 \%$. We assume that utility in each of our models is defined according to (12), (21) and (28). The intertemporal elasticity of consumption, $\sigma=1.5$ and that of the labour supply is $\Psi=1$. In the MIU model, we set $b$, the inverse of the interest elasticity of money demand to 2.56 in line with Chari et al (2000). We assume an elasticity of substitution between individual varieties, $\theta=7.67$, which yields a steady state mark-up over unit costs of $15 \%$, a value commonly used in the literature. We follow Erceg et al (2000) in setting the elasticity of substitution between varieties of labour to 4.03 , which yields a mark-up over the marginal rate of substitution between consumption and leisure of some $33 \%$. We assume the probability that a firm can not change prices in a given period to be $\alpha=0.5$, which implies that firm receive a signal to adjust prices on average every 2 quarters. This lies between the commonly used value of $\alpha=0.67$ (every 3 quarters) as suggested by Canzoneri et al. (2004) and the much lower values in Bils and Klenow (2004) who suggest a value of around 0.3 suggesting firms change prices on average every 1.4 quarters. We assume that unions re-optimize wages on average once every 4 quarters. On the production side of the model, we assume an annualised depreciation rate of the capital stock of $10 \%$ and a share of capital in production of $33 \%$. The adjustment cost parameter, $\epsilon_{K}$, is chosen so as to match to the data the relative volatility of investment to GDP generated by the calibrated models.

We summarize our chosen parameter values in Table 1 
Table 1: Parameters of the models

\begin{tabular}{cccc}
\hline \hline Parameter & Estimate & Parameter & Estimate \\
\hline$\beta$ & 0.984 & $\theta_{w}$ & 4.03 \\
$\theta$ & 7.67 & $\delta$ & 0.025 \\
$\bar{N}$ & 0.67 & $\epsilon_{K}$ & calibrated \\
$\bar{L}$ & 0.33 & $s_{K}$ & 0.33 \\
$\sigma$ & 1.5 & $\alpha$ & 0.5 \\
$\Psi$ & 1 & $\alpha_{w}$ & 0.75 \\
\hline \hline
\end{tabular}

\subsection{Driving processes}

There are two types of shocks hitting our model economies; there are shocks to total factor productivity and there are 'monetary policy shocks', defined either as shocks to the interest rate rule or shocks to the money growth rate. We wanted to focus on the post-Volcker era as we think linearized models stand the best chance of matching the data in this relatively stable economic period. However, related studies such as Canzoneri et al. (2004) and others, suggest that measured TFP over such a relatively short sample may be subject unduly to cyclical factors, and we found this also. Hence, we opted to estimate TFP over a longer sample period, whilst estimating our monetary policy rule (and shocks) over the post-Volcker period. Estimating the monetary policy shock over the whole sample period would have compounded our difficulties as we would have run up against issues such as nominal regime shifts, as documented by Gavin and Kydland (1999). These issues do not however apply when estimating the money growth shock, as these are commonly estimated over the whole post war period, see Danthine and Kurmann (2004) and Kollmann (2005) for example.

We measure total factor productivity by the Solow residual. We estimate the Solow residual using quarterly US data from $1960 q 1$ through $2003 q 4$. We estimate the following relationship:

$$
\ln A_{t}=\rho \ln A_{t-1}+\varepsilon_{A, t},
$$

where $\ln A$ the $\log$ of the linearly detrended Solow residual ${ }^{1}$. The estimated coefficient $\rho$ and the standard error of the equation are shown in Table 2

Table 2: Estimated Solow residual

\begin{tabular}{cc}
\hline \hline$\rho$ & $\sigma_{\varepsilon A}$ \\
0.94343 & $8.424 \times 10^{-3}$ \\
$(39.76)$ & \\
\hline
\end{tabular}

To estimate a monetary policy feedback rule, we choose a shorter sample period from $1984 q 1$ to $2003 q 4$. We estimate the following Taylor rule using ordinary least squares:

\footnotetext{
${ }^{1}$ In the appendix we provide details of how we constructed our Solow Residual.
} 


$$
i_{t}=c+\phi_{i} i_{t-1}+\phi_{\pi} \pi_{t}+\phi_{\bar{y}}\left(y_{t}-\bar{y}_{t}\right)+\varepsilon_{i, t} .
$$

Our results are given in Table 3

Table 3: Estimated Taylor rule coefficients

\begin{tabular}{ccccc}
\hline \hline$c$ & $\phi_{i}$ & $\frac{\phi_{\pi}}{\left(1-\phi_{i}\right)}$ & $\frac{\phi_{\bar{y}}}{\left(1-\phi_{i}\right)}$ & $\sigma_{\varepsilon i}$ \\
0.000 & 0.937 & 1.506 & 0.4997 & $1.225 \times 10^{-3}$ \\
$(0.14)$ & $(35.24)$ & $(2.72)$ & $(3.17)$ & \\
\hline
\end{tabular}

$t$-statistics are in parentheses.

We measure the growth rate of money by the log difference of between period $\mathrm{t}$ and period $\mathrm{t}-1$ per capita US M1 money stock.

$$
\ln \left(1+g_{M_{t}}\right)=\left[\ln \left(M 1_{t}\right)-\ln \left(\text { pop }_{t}\right)\right]-\left[\ln \left(M 1_{t-1}\right)-\ln \left(\text { pop }_{t-1}\right)\right]
$$

and estimate the shock to money growth process using quarterly US data from $1960 q 2$ through $2003 q 4$ as:

$$
g_{M_{t}}=c+\rho_{g} g_{M_{t-1}}+\varepsilon_{g, t}
$$

Table 4: Estimated money growth rule coefficients

\begin{tabular}{ccc}
\hline \hline$c$ & $\rho_{g}$ & $\sigma_{\varepsilon i}$ \\
0.003 & 0.662 & $8.592 \times 10^{-3}$ \\
$(3.91)$ & $(11.67)$ & \\
\hline
\end{tabular}

\section{Unconditional second moments}

Having solved the models, we now analyze the unconditional second moments generated by the model economies for the different models and under the different monetary policy frameworks. The second column of table 5 reports selected second moments from quarterly US data for the period 1960:1 to 2003:4. Both the data and the model output are logged and Hodrick-Prescott filtered. ${ }^{2}$. The appendix describes in detail our data sources and construction of data.

Models with interest rate rules. Columns 3, 4 and 5 contain the second moments of the MIU, ST and CIA models. In each case we set the capital adjustment cost parameter, $\epsilon_{K}$ in such a way that the model generates a filtered series for investment that is 3.19 times as volatile as the filtered series for GDP. ${ }^{3}$ The MIU and the CIA models are able to match the standard deviation of GDP

\footnotetext{
${ }^{2}$ The time series for the policy rate is only $\mathrm{H}-\mathrm{P}$ filtered, not logged.

${ }^{3}$ We define capital adjustment costs as $\phi(x / k)$ where $\mathrm{x}$ is investment and $\mathrm{k}$ is the capital stock. The capital adjustment cost parameter is defined as: $\frac{\phi^{\prime \prime}(x / k)(x / k)}{\phi^{\prime}(x / k)}=\epsilon_{K}$.
} 
for this calibration. The shopping time model is slightly more volatile than the data following this calibration strategy. Whereas our calibration strategy aims to match the relative volatility of investment, all models across both monetary policy frameworks fail to match the relative volatility of consumption. Under an interest rate rule, all three models do a reasonable job at matching the volatility of hours, real wages and inflation relative to the volatility of output. All three models generate filtered time series for wage inflation and interest rates that are less volatile than the data. Cross-correlations between our variables of interest and GDP have the correct sign for consumption, investment, hours, real wages and wage inflation, but the correct magnitude only for the first three variables. All three models generate counter-cyclical time series for inflation and the policy rate, whereas the data suggest a pro-cyclical relationship for each. All three models under-predict the persistence of GDP, consumption, investment and inflation. Related work by Nolan and Thoenissen (2005) suggests that the negative cross-correlation between inflation and GDP may be attributed to the presence of sticky wages, and that the counter-cyclicality of both the policy rate and inflation is robust to the introduction of firm-specific capital and/or to changes in the Calvo parameter on prices.

A striking feature is how similar the second moments are for all three models in the case of an interest rate feedback rule. This suggests that the differences in the first-order conditions that arise due to the non-separability of consumption and money in the utility function implied by the ST and CIA models do not play a significant role in the dynamics of the models. We now turn to the models under the assumption that monetary policy is characterized by a money growth rule.

Models with money growth rules. The MIU and ST models generate filtered time series for GDP that are more than twice as volatile as the data, unlike the CIA model which matches the standard deviation of GDP quite closely. Compared to the models under an interest rate rule, the relative standard deviation of hours worked is too high (more volatile than the data) and that of the real wage too low. The MIU and ST models match the relative volatility of inflation, whereas the CIA model is able to match the relative standard deviation of wage inflation. Along these two dimensions, the money growth rule comes closer to the data than an interest rate rule. Interestingly, this is also the case for the interest rate, but only when a money growth rule is combined with a cash-in-advance constraint. The models under a money growth rule overcome the problem of counter-cyclical inflation and nominal interest rates, but yield a counter-cyclical real wage, which is in contrast to the data. Under a money growth rule, only the CIA model generates cross-correlations that have the correct sign for all variables analysed. Canzoneri et al (2004) argue that the counter-cyclicality of inflation and the policy rate suggests a missing or incorrectly specified demand shock. Our analysis suggests an important role for the way money and monetary policy are modelled.

The MIU and ST models generate even less persistence of GDP and its components under a money growth rule than under an interest rate rule and 
Table 5: Data and model economies: 1960:1 - 2003:4

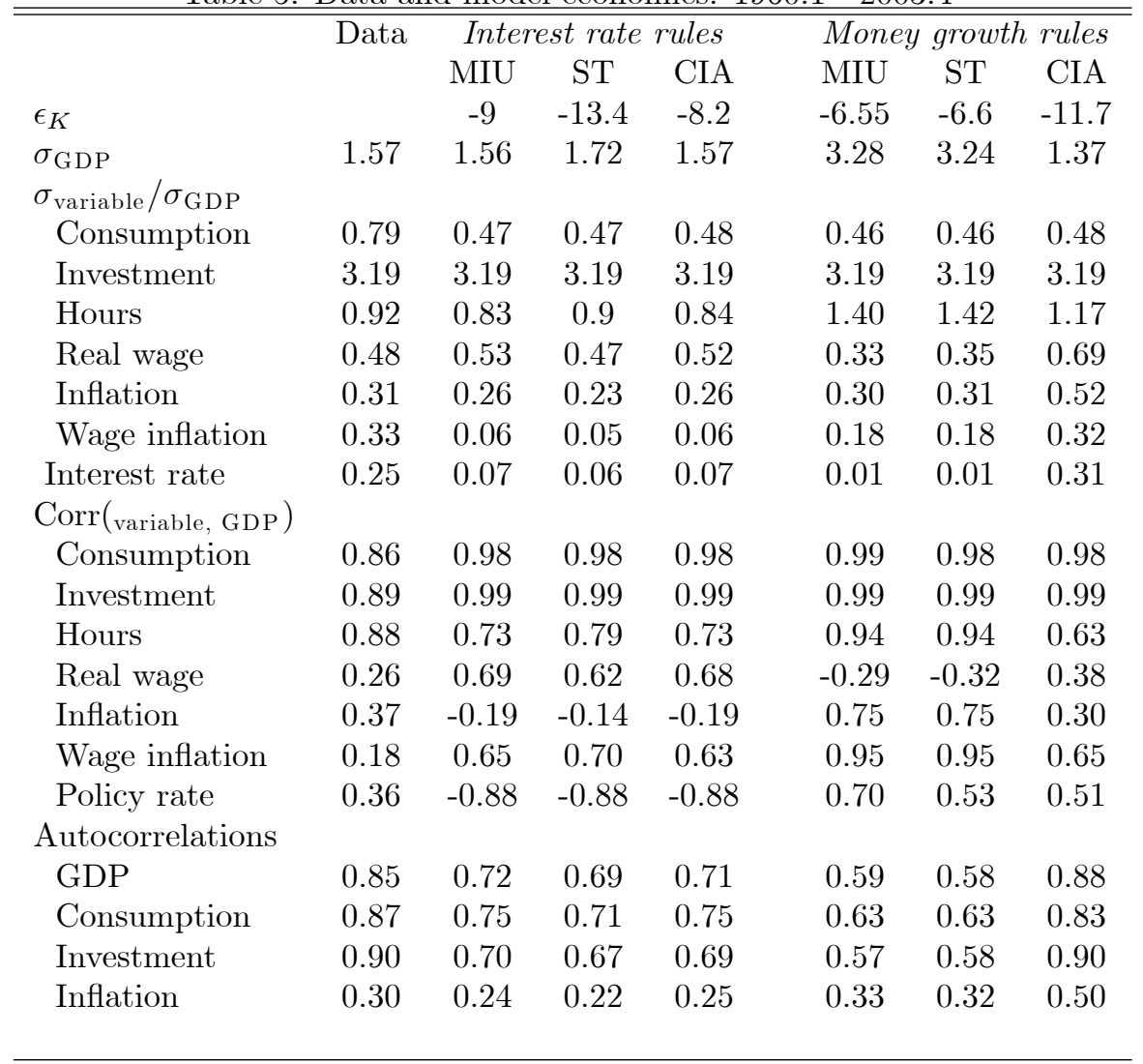

are therefore even further away from the data. The CIA model generates more persistence under a money growth rule than under an interest rule and comes close to matching the first order autocorrelation coefficient of GDP and its components, but somewhat overestimates the persistence of inflation.

Overall, the MIU and ST models appear to be further away from the data under a money growth rule than under an interest rate rule. The CIA model however comes closer to the data under a money growth rule than under an interest rate rule. Before we attempt to rank the models according to their ability to match the unconditional second moments of the data using econometric techniques, the next section analyses and compares the short-run dynamics of the models using impulse response functions.

\section{Impulse responses}

In this section, we use impulse response functions to analyze how our calibrated models react to monetary policy as well as technology shocks. The calibration 
of each model, in particular the calibration of the capital adjustment cost parameter, corresponds to the calibration used to generate the moments summarized in table 5. Throughout, the response of a variable in the MIU model is denoted by a solid line (-), the response of a variable in the ST model is denoted by a dashed (- -) line and the response of a variable in the CIA model by a dotted line $(\cdots)$.

Monetary shocks in models with an interest rate feedback rule. We know from table 5 that under an interest rate rule the different models produce very similar second moments. This result is borne out by the different panels of figure 1. Apart from the demand for real money balances, the dynamics of output, consumption, investment, employment, real wage, marginal cost, the policy rate and inflation are very similar across model specifications. In response to an unexpected cut in the policy rate, output and its components rise. Contrary to VAR evidence, the response of these three variables does not, however, have a 'hump' shape such that the greatest effect of a monetary easing occurs some quarters after the shock. Marginal cost and inflation also increase in response to a monetary easing. Because prices adjust more frequently than nominal wages, the real wage falls initially. Employment, which is demand determined, rises along with the increase in output and the fall in the real wage. The policy rate reacts endogenously to the interest rate shock. In response to the rise in inflation and a positive output gap, the policy maker raises interest rates following the shock, but not by enough to stop the policy rate from falling relative to its initial equilibrium value.

Technology shocks in models with an interest rate feedback rule. As in the previous example, all three models display similar dynamics in response to an increase in total factor productivity when monetary policy is modelled via an interest rate feedback rule. In figure 2, output and its components rise in response to a technology shock. Employment and the real wage also increase. The 'hump' shape of these response functions reflects, to some degree, the autocorrelation of the productivity innovation. A technology shock lowers the marginal costs and thus inflation. The policy maker responds to the fall in inflation by lowering the nominal interest rate.

The conclusion we can draw from our impulse response analysis thus far is that in terms of short-run dynamics, the way we introduce money into our models appears not to be crucial as long as we model monetary policy via an interest rate feedback rule. Next, we analyze our three models under the assumption that monetary policy is modelled by a money growth rule.

Monetary shocks in models with a money growth rule. Figure 3 shows that when monetary policy is modelled by a money growth rule, an increase in the growth rate of the money supply has significantly different dynamic implications for the cash-in-advance model than for the money-in-the-utility function or the shopping time models. Unlike the CIA model, the dynamics of the MIU and ST models are very similar to their counterparts in the interest rate rule models. Importantly, in the CIA model the response of output, consumption, investment and employment is 'hump' shaped. The impulse responses suggest that it takes several quarters for the maximum effect of a monetary easing to impact on 
output and its components as well as on employment. The model does not succeed at generating a liquidity effect whereby the nominal interest rate falls in response to a rise in money growth rate. Instead, the nominal interest rate rises in response to a monetary expansion. A partial explanation of this response is to be found in the response of inflation. Compared to the MIU and ST models, inflation rises by less, and is more persistent, but is still highest in the initial period of the shock.

Technology shocks in models with a money growth rule. Figure 4 shows impulse response functions with respect to a $1 \%$ technology shock when monetary policy is modelled by a money growth rule. Unlike for monetary shocks, the CIA model does not display qualitatively different dynamics than the alternative models following a technology innovation. Because agents need to accumulate real money balances for consumption and investment purposes, output and its components in the CIA model appears to be less volatile but more persistent than its alternatives. Employment initially declines by more in the CIA model than in the two alternative specifications. Note also that the negative response to employment is much more pronounced in the models under a money growth rule than under an interest rate rule. Where the MIU, ST and CIA models differ most is the response of the policy rate. Whereas the interest rate in the first two models barely reacts to a technology shock, the interest rate in the CIA model declines on impact (similar in magnitude to its response under an interest rate rule - see figure 2), and rises above its steady state value along the adjustment path.

The main conclusion we can draw from our analysis of impulse response functions is that the CIA model, when combined with a money growth rule can generate 'hump' shaped responses in output and its components following a monetary shock. ${ }^{4}$ We find that this 'hump' shape arises only in the combination of CIA and money growth rules. Taken individually, neither feature is able to generate such a response. Our findings mirror those of Wang and Wen (2005) who also find that the CIA constraint in conjunction with a money growth rule can generate 'hump' shaped responses of output to money growth shocks.

We have analysed the unconditional second moments as well as the impulse response functions of three models across two monetary policy specifications. We have seen that under an interest rate feedback rule, it is difficult to distinguish the thee models. We found that in a money growth rule specification, the CIA model had certain desirable features not shared by either the MIU or the ST models. Each model and specification appears to have advantages as well as disadvantages that makes a ranking based on the current criteria difficult and imprecise. In the next section, we describe econometric methods to compare a set of second moments of the model (capturing the variables we discussed in table 5) with those of the data. Importantly, these methods allows us to compare non-nested models with the data and with one another.

\footnotetext{
${ }^{4}$ Some of our (not reported) sensitivity analysis suggests that the hump shape in output is less pronounced when the CIA constraint applies only to consumption and not consumption and investment.
} 


\section{Comparison of models based on data and model covariance matrices}

Beginning with Watson (1993), there has been substantial research on formal empirical validation of dynamic macroeconomic models based on the degree of conformity in selected moments of the state variables, or second-order comparison over selected range of frequencies ${ }^{5}$. We use the empirical approach proposed in Bhattacharjee and Chadha (2005) to select among different DSGE models for the role of money, based on comparison of the variance-covariance matrix (VCM) of the data with that of alternative competing models.

\subsection{Measuring the distance between data and model VCMs}

Our approach to measuring the distance between data and model VCMs is distinct from much of the literature and offers several advantages in the current context. First, the approach focuses on model selection rather than testing model fit, which is appropriate for assessing the fit of 'false' macroeconomic models ${ }^{6}$. This is in contrast to the use of formal hypothesis tests which implicitly assume a state of the world where the model is at least nearly true (Canova and Ortega, 2000). Second, existing methods are often difficult to apply with calibrated models (not estimated using a likelihood-based approach), or when the models are non-nested (Watson, 1993; Canova and Ortega, 2000); our approach enables evaluation of non-nested and calibrated models, and is therefore appropriate for the current application. Third, the methods explicitly consider parsimonious models populated by a small number of shocks. Many of the methods proposed earlier in the literature are difficult to implement when the model is rank-deficient, i.e., having a rank lower than the number of state variables (Watson, 1993). Finally, we use both measures that allow sampling variability only in the data, as well as those admitting sampling variability both in data and in simulations ${ }^{7}$.

As described in Section 4, we solve the models using the solution algorithm of King and Watson $(1998,2002)$, and estimate moments in the frequency domain. The asymptotic matrix of second moments of the state variables estimated using the King and Watson $(1998,2002)$ algorithm constitute the model VCM for each of the models considered here. Our econometric framework accepts that all the competing models are possibly 'false' - hence, none of the simulated model VCMs may be statistically indistinguishable from actual data, except in very small samples. These competing models may not be nested within each other. Further, being driven by a small number of shocks, the models will almost certainly be rank-deficient, in the sense that the model VCMs will have a rank less than the number of state variables.

\footnotetext{
${ }^{5}$ See Canova and Ortega (2000) for a review, and Diebold, Ohanian and Berkowitz (1998), Ireland (2004) and Bhattacharjee and Chadha (2005) for recent contributions to the literature.

${ }^{6}$ See also Diebold et al. (1998).

${ }^{7}$ See Canova and Ortega (2000) for a discussion. The relevance of this classification is explained in further detail in Bhattacharjee and Chadha (2005).
} 
Denote by $\left[\Sigma_{0}\right]_{m \times m}$ the full-rank data VCM estimated using $n$ data points; $\rho\left(\Sigma_{0}\right)=m$, where $\rho($.$) denotes rank of a square matrix. \left[\Sigma_{M_{1}}\right]_{m \times m},\left[\Sigma_{M_{2}}\right]_{m \times m}$, $\left[\Sigma_{M_{3}}\right]_{m \times m}, \ldots$ are estimated asymptotic VCMs of competing models $M_{1}, M_{2}$, $M_{3}, \ldots$. Since all our competing models are parsimonious, the model VCMs are rank deficient $\left(p_{j}=\rho\left(\Sigma_{M_{j}}\right) \leq \rho\left(\Sigma_{0}\right)=m\right)$. In the following, we consider a single model VCM, $\Sigma_{M}$, having rank $p(<m)$ and describe measures of the distance between this model VCM and the data VCM, $\Sigma_{0}{ }^{8}$.

We use several distance measures to evaluate the various competing DSGE models by the closeness of their simulated asymptotic VCMs to the VCM of the data. These measures can be classified into three classes based on the nature of sampling variability. First, we may consider informal or naive measures that quantify the numeric proximity of the data VCM with various model VCMs, without considering the nature of sampling variability. Second, we present methods based on a testing approach that considers the asymptotic simulated model VCM as given, and asks the question: Given sampling variability in the data, could the data VCM have been generated by sampling using the computed model VCM as the data generating process? Given that our models are 'false', we expect the answer to this testing question to be negative, but we can still interpret the p-value of the test, or the test statistic adjusted for the degrees of freedom, as a measure of the distance between data and model VCMs. Third, we assume sampling variability in both data and the simulations, and use the notion of distance between distributions (such as the Kullback-Leibler distance) to evaluate the validity of the different competing models.

\subsubsection{Informal or Naive approach}

Without any distributional assumption, we may informally measure the distance between $\Sigma_{M}$ and $\Sigma_{0}$ by the Mean Absolute Errors (MAE):

$$
M A E=\frac{1}{m^{2}} \sum_{i=1}^{m} \sum_{j=1}^{m}\left|\widetilde{\sigma}_{i, j}\right|
$$

where $\widetilde{\Sigma}=\left(\left(\widetilde{\sigma}_{i j}\right)\right)_{m \times m}=\Sigma_{M}-\Sigma_{0}$. This measure loosely formalizes the informal comparison of moments commonly adopted in the literature, and as we have conducted earlier in Section 5. The method has some possible limitations in that (a) it does not admit any probabilistic comparisons, and (b) it gives the covariances double the weight of the variances. On the other hand, the measure is assumption-free and simple to use, and potentially useful for eye-balling the differences between the data and model VCMs. Root Mean Squared Errors (RMSE) is another similar measure of distance; here we do not use this measure since it is very similar to the Nagao's test statistic described below.

\footnotetext{
${ }^{8} \mathrm{An}$ alternative strategy is to take a frequency domain approach and compare second-order properties only over a selected range of frequencies (Diebold et al., 1998). While this strategy is consistent with our framework, in this paper we focus on comparison of unconditional moments of the state variables without decomposing variation across frequencies.
} 


\subsubsection{Testing approach: Sampling variability in data but not in sim- ulations}

We explicitly take the view that all our competing models are 'false'. Thus, in the statistical testing problem

$$
H_{0}: \Sigma_{0}=\Sigma_{M} \text { versus } H_{1}: \Sigma_{0} \neq \Sigma_{M}
$$

we expect to reject the null hypothesis that the the data VCM is the same as the model VCM, at least for large enough data. Nevertheless, we propose the p-values associated with the test statistics as measures of the distance between data and alternative competing models.

Note that the rank of the model VCM is given by the sum of number of shocks in the model and the predetermined variables. Hence, since many of our models are populated by a small number of shocks, we explicitly consider the situation when the data VCM is full-rank, but the model VCM is not. Therefore, we have a setup where, under $H_{0}$, the estimated full-rank data VCM, $\widehat{\Sigma}_{0, n}$, asymptotically converges to the rank-deficient matrix $\Sigma_{M}$.

The asymptotics of this setup can be motivated as follows. Under the null hypothesis, $\Sigma_{M}$ (and by implication $\Sigma_{0}$ ) is driven by $p(<m)$ sources of variation, which include the shocks in the model as well as predetermined variables. However, at each finite sample size, all state variables may be subject to some random measurement error which has a very small variance compared to each source of variation in $\Sigma_{0}$. Further, this variance decreases with sample size and asymptotically goes to zero, so that the sequence of full-rank matrices $\widehat{\Sigma}_{0, n}$ converges to the rank-deficient matrix $\Sigma_{M}$. We consider stationary state variables with zero means, and assume multivariate normality.

If $\Sigma_{M}$ were full-rank, we could choose from a wide range of tests borrowed from the statistics literature (Muirhead, 1982), among which Bartlett's (1954) $B$-test and Nagao's (1973) $N$-test are the most popular. However, since none of our DSGE models is full rank, these tests cannot be directly applied to our situation. We describe below a modification of Nagao's test to this situation.

Further, a modification of the Nagao's test for rank-deficient situations has been proposed by Ledoit and Wolf (2002). They show consistency of their test statistic when the number of variables $(m)$ is larger than the sample size $(n \equiv p)$, and derive asymptotic distribution under the assumption that both $n$ and $p$ increase to infinity asymptotically. To the extent that this test is consistent in a rank-deficient setup, the Ledoit and Wolf (2002) test statistic can be very useful. A particularly promising aspect of this test is its excellent performance, even in very small samples (Ledoit and Wolf 2002, Tables 5 and 6). However, since our DGP is different in that our population VCM is rank-deficient by design, the test is not consistent in this situation ${ }^{9}$. Further. the asymptotic setup in our case is fundamentally different from Ledoit and Wolf (2002), and therefore the large sample properties are not similar. Here we propose a modification of

\footnotetext{
${ }^{9}$ See Bhattacharjee and Chadha (2005) for further details.
} 
the test for our setup using related research on singular Wishart distributions (Uhlig 1994, Srivastava 2003) ${ }^{10}$.

As described earlier, the reason the model VCM is rank-deficient is because it is parsimonious and driven by a small number of shocks and pre-determined variables. Thus a good model VCM will approximately correspond to a data VCM that is full-rank, but has only a limited number of large eigenvalues; these eigenvalues (and corresponding eigenvectors) represent the main drivers of the data VCM and correspond to the leading eigenvectors of the VCM of our good model. Therefore, the idea behind our modifications is to project the data VCM onto a lower dimensional subspace which is spanned by the leading eigenvectors of the model VCM. On this subspace, both the data and the model VCMs will be full-rank, and can therefore be compared.

Following Srivastava (2003), we write the singular value decomposition of $\Sigma_{M}$ as:

$$
\begin{aligned}
\Sigma_{M}=\left[\begin{array}{lll}
\Gamma_{1_{m \times p}}^{\prime} & : & \Gamma_{2_{m \times(m-p)}}^{\prime}
\end{array}\right] \cdot\left[\begin{array}{cc}
\Lambda_{p \times p} & 0_{p \times(m-p)} \\
0_{(m-p) \times p} & 0_{(m-p) \times(m-p)}
\end{array}\right] \\
\qquad \cdot\left[\begin{array}{c}
\Gamma_{1_{p \times m}} \\
\cdot \cdot \\
\Gamma_{2_{(m-p) \times m}}
\end{array}\right] \\
=\Gamma_{1}^{\prime} \cdot \Lambda \cdot \Gamma_{1},
\end{aligned}
$$

where $\Lambda=\operatorname{diag}\left(\lambda_{1}, \ldots, \lambda_{p}\right)$ is the diagonal matrix containing the $p$ positive eigenvalues $\lambda_{1} \geq \ldots \geq \lambda_{p}$ of $\Sigma_{M}$, and the rows of $\Gamma_{1}$ contain the corresponding eigenvectors. Hence, under the stated null hypothesis (35), we have:

$$
\begin{aligned}
& {\left[\begin{array}{cc}
I_{p \times p} & 0 \\
0 & 0
\end{array}\right]=\left[\begin{array}{cc}
\Lambda_{p \times p}^{-1 / 2} & 0 \\
0 & 0
\end{array}\right] \cdot\left[\begin{array}{c}
\Gamma_{1_{p \times m}} \\
\cdot \cdot \\
\Gamma_{2_{(m-p) \times m}}
\end{array}\right] \cdot \Sigma_{M} .} \\
& {\left[\begin{array}{lll}
\Gamma_{1_{m \times p}}^{\prime} & : & \Gamma_{2_{m \times(m-p)}}^{\prime}
\end{array}\right] \cdot\left[\begin{array}{cc}
\Lambda_{p \times p}^{-1 / 2} & 0 \\
0 & 0
\end{array}\right]} \\
& =\left[\begin{array}{c}
\left(\Lambda^{-1 / 2} \cdot \Gamma_{1}\right)_{p \times m} \\
0_{(m-p) \times m}
\end{array}\right] \cdot \Sigma_{M} \cdot\left[\left(\Gamma_{1}^{\prime} \cdot \Lambda^{-1 / 2}\right)_{m \times p} 0_{m \times(m-p)}\right] \\
& =\left[\begin{array}{c}
\left(\Lambda^{-1 / 2} \cdot \Gamma_{1}\right)_{p \times m} \\
0_{(m-p) \times m}
\end{array}\right] \cdot \Sigma_{0} \cdot\left[\begin{array}{ll}
\left(\Gamma_{1}^{\prime} \cdot \Lambda^{-1 / 2}\right)_{m \times p} & 0_{m \times(m-p)}
\end{array}\right] \\
& =\left[\begin{array}{cc}
\left(\Lambda^{-1 / 2} \cdot \Gamma_{1} \cdot \Sigma_{0} \cdot \Gamma_{1}^{\prime} \cdot \Lambda^{-1 / 2}\right)_{p \times p} & 0 \\
0 & 0
\end{array}\right] .
\end{aligned}
$$

Hence, the null hypothesis can be restated as:

$$
H_{0}: \Sigma_{0}^{(M)}=I_{p \times p},
$$

\footnotetext{
${ }^{10}$ Srivastava (2003) uses the name pseudo Wishart matrices for the distribution of sample cross-product estimated VCMs which are rank-deficient by design, rather than because of shortage of data.
} 
where

$$
\Sigma_{0}^{(M)}=\left(\Lambda^{-1 / 2} \cdot \Gamma_{1} \cdot \Sigma_{0} \cdot \Gamma_{1}^{\prime} \cdot \Lambda^{-1 / 2}\right)_{p \times p}
$$

can be estimated by

$$
\widehat{\Sigma}_{0}^{(M)}=\Lambda^{-1 / 2} \cdot \Gamma_{1} \cdot \widehat{\Sigma}_{0, n} \cdot \Gamma_{1}^{/} \cdot \Lambda^{-1 / 2}
$$

using the singular value decomposition of the given rank-deficient $\operatorname{VCM} \Sigma_{M}$. The above construction basically projects the full-rank data VCM onto the lower-dimensional subspace spanned by the $p$ eigenvectors of the model VCM corresponding to the leading non-zero eigenvalues.

Bartlett's, Nagao's and Ledoit-Wolf tests can all be modified to this new testing problem. For the test $H_{0}: \Sigma_{0}^{(M)}=I_{p \times p}$ against the omnibus alternative $H_{1}: \Sigma_{0}^{(M)} \neq I_{p \times p}$, the modified Nagao test statistic $\left(N_{n e w}\right)$ and Ledoit-Wolf test statistic $\left(W_{\text {new }}\right)$ on the lower dimensional full-rank subspace defined above are given by

$$
\begin{aligned}
N_{\text {new }}= & \frac{1}{p} \cdot \operatorname{tr}\left(\widehat{\Sigma}_{0}^{(M)}-I_{p \times p}\right)^{2}, \\
& \frac{n p}{2} \cdot N_{\text {new }} \sim \chi^{2}\left(\frac{p(p+1)}{2}\right) \quad \text { under } H_{0} \text { as } n \rightarrow \infty
\end{aligned}
$$

and

$$
\begin{aligned}
W_{\text {new }}= & \frac{1}{p} \cdot \operatorname{tr}\left(\widehat{\Sigma}_{0}^{(M)}-I_{p \times p}\right)^{2}-\frac{p}{n} \cdot\left[\frac{1}{p} \cdot \operatorname{tr}\left(\widehat{\Sigma}_{0}^{(M)}\right)\right]^{2}+\frac{p}{n} \\
& \frac{n p}{2} \cdot W_{n e w} \sim \chi^{2}\left(\frac{p(p+1)}{2}\right) \quad \text { under. } H_{0} \text { as } n \rightarrow \infty
\end{aligned}
$$

where $\operatorname{tr}($.$) denotes trace of a square matrix.$

Bhattacharjee and Chadha (2005) show that both $N_{\text {new }}$ and $W_{\text {new }}$ test statistics are consistent and have the mentioned asymptotic distribution when the rank of the model VCM is fixed as sample size increases. In certain situations, one can imagine that as more data accumulates, the researcher may wish to increase the complexity of the model. The modified Ledoit-Wolf test will be consistent even in such a situation and have the stated asymptotic distribution, so long as the ratio of the model VCM rank and the sample size converges to a finite limit asymptotically. Further, Ledoit and Wolf (2002) demonstrate excellent small sample properties of their test, which also carries through in our modification.

\subsubsection{Distance between distributions: Sampling variability in both data and simulations}

Evaluation of models based on distances, such as the Kullback-Leibler Information Criteria (KLIC), between distributions defined by data and model VCMs 
is not straightforward, since model VCMs are usually rank-deficient (Watson, 1993). Bhattacharjee and Chadha (2005) propose a modification to the KLIC by restricting attention to the subspace of the vector of state variables on which the model VCM has a "proper" density. Like the testing approach, we restrict attention to a lower dimensional subspace of the state variables over which a proper density can be defined.

The KLIC between the distributions of data (mean zero, VCM $\Sigma_{0}$ ) and model (mean zero, VCM $\Sigma_{M}$ ) is defined as:

$$
\begin{aligned}
\operatorname{KLIC}\left(\Sigma_{0}, \Sigma_{M}\right) & =E_{f\left(. ; 0, \Sigma_{0}\right)} \ln \frac{f\left(Y ; 0, \Sigma_{M}\right)}{f\left(Y ; 0, \Sigma_{0}\right)} \\
& =\int_{-\infty}^{\infty} \ln \frac{f\left(y ; 0, \Sigma_{M}\right)}{f\left(y ; 0, \Sigma_{0}\right)} f\left(y ; 0, \Sigma_{0}\right) d y,
\end{aligned}
$$

where $f(. ; 0, \Sigma)$ is the density function of the multivariate normal distribution with zero mean and VCM $\Sigma$. However, since $\Sigma_{M}$ is rank deficient, $f\left(y ; 0, \Sigma_{M}\right)$ is not a proper density; the density is zero almost everywhere.

As before, we consider the singular value decomposition of the model VCM (Equation 36):

$$
\Sigma_{M}=\lambda_{1} \cdot \underline{e}_{1} \cdot \underline{e}_{1}^{\prime}+\lambda_{2} \cdot \underline{e}_{2} \cdot \underline{e}_{2}^{\prime}+\ldots+\lambda_{p} \cdot \underline{e}_{p} \cdot \underline{e}_{p}^{\prime}+0 \cdot \underline{e}_{p+1} \cdot \underline{e}_{p+1}^{\prime}+\ldots+0 . \underline{e}_{m} \cdot \underline{e}_{m}^{\prime},
$$

where $p=\rho\left(\Sigma_{M}\right)<m$ is the rank of the model VCM, $\lambda_{1} \geq \lambda_{2} \geq \ldots \geq \lambda_{p}$ are the positive eigenvalues (elements of the diagonal matrix $\Lambda_{p \times p}$ ), and $\underline{e}_{1}, \underline{e}_{2}, \ldots, \underline{e}_{p}$ are the corresponding eigenvectors (columns of the matrix $\Gamma_{1_{m \times p}}^{\prime}$ ).

Then, the density function of this rank-deficient model (mean zero, VCM $\Sigma_{M}, \rho\left(\Sigma_{M}\right)=p<\rho\left(\Sigma_{0}\right)=m$ ) on the subspace spanned by only the $p$ leading eigenvectors is given by:

$$
f\left(\underline{y}_{m \times 1} ; 0, \Sigma_{M}\right)=\frac{1}{(2 \pi)^{m / 2}\left(\lambda_{1} \cdot \lambda_{2} \ldots . \lambda_{p}\right)^{1 / 2}} \cdot \exp \left(-\frac{1}{2} \underline{y}^{\prime} \Sigma_{M}^{-} \underline{y}\right),
$$

where

$$
\Sigma_{M}^{-}=1 / \lambda_{1} \cdot \underline{e}_{1} \cdot \underline{e}_{1}^{\prime}+1 / \lambda_{2} \cdot \underline{e}_{2} \cdot \underline{e}_{2}^{\prime}+\ldots+1 / \lambda_{p} \cdot \underline{e}_{p} \cdot \underline{e}_{p}^{\prime}
$$

is the Moore-Penrose inverse of $\Sigma_{M}$. The density of the data VCM (full-rank) is computed in the usual way, and therefore the Kullback-Leibler distance can be computed.

Computational intensity can be an issue with the implementation of this method. Following Bhattacharjee and Chadha (2005), we reduce computations by estimating KLIC using a sampling approach, where the KLIC estimate is obtained by computing sample means of log-likelihood ratios, using either a Monte Carlo or a bootstrap sample from the actual distribution of the state variables. Here, we present the estimates based on the bootstrap given by:

$$
\operatorname{KLIC}_{(B S)}\left(\Sigma_{0}, \Sigma_{M}\right)=\frac{1}{N_{0}^{B S}} \sum_{i=1}^{N_{0}^{B S}} \ln \frac{f\left(y_{i} ; 0, \Sigma_{M}\right)}{f\left(y_{i} ; 0, \Sigma_{0}\right)},
$$


where the KLIC is estimated by a sample average of the log-ratios of the two likelihoods taken over a bootstrap sample of size $N_{0}^{B S}$ drawn by resampling from the distribution of the data. In practice, the bootstrap estimator may have an advantage over the Monte Carlo estimator, in that it relies less heavily on the Gaussian distributional assumption.

\subsection{Taking the models to the data}

We apply the above methods to measure distance between data and model VCMs for our different candidate models. The state variables that we compare across all models and specifications are: logged and Hodrick-Prescott filtered series for consumption, federal funds rate ${ }^{11}$, investment, inflation, hours worked, GDP, real wages and wage inflation. Selected results are presented in table $6^{12}$.

As discussed above, we intend to use the p-values from the two tests as well as the estimated Kullback-Leibler distances to rank the models in terms of the closeness of their VCMs with that from the data. Further, since we intend to use the tests to conduct model selection among "false" models, we also expect the null hypothesis (that the data VCM is the same as the model VCM) to be rejected in each case. In other words, we expect the p-value to be close to zero. This indeed turns out to be the case, as the high values of the modified Nagao and modified Ledoit-Wolf test statistics show (Table 6). However, since all models and specifications have the same degrees of freedom, we can rank the models by the value of the modified Nagao and Ledoit-Wolf test statistics (presented in Table 6), as well as by their respective Kullback-Leibler distances and Mean Absolute Errors ( $M A E)$.

Table 6: Test Statistics

\begin{tabular}{lccccccc}
\hline \hline & \multicolumn{3}{c}{ Interest rate rules } & \multicolumn{3}{c}{ Money growth rules } \\
& MIU & ST & CIA & MIU & ST & CIA \\
& & & & & & \\
$K L I C(B S)$ & $1328(5)$ & $1382(6)$ & $811(3)$ & $696(2)$ & $1016(4)$ & $22.9(1)$ \\
$N_{\text {new }}$ & $6.07 \mathrm{e}^{8}(5)$ & $6.64 \mathrm{e}^{8}(6)$ & $2.21 \mathrm{e}^{8}(3)$ & $1.66 \mathrm{e}^{8}(2)$ & $3.58 \mathrm{e}^{8}(4)$ & $2.64 \mathrm{e}^{4}(1)$ \\
$W_{\text {new }}$ & $6.02 \mathrm{e}^{8}(5)$ & $6.06 \mathrm{e}^{8}(6)$ & $2.20 \mathrm{e}^{8}(3)$ & $1.65 \mathrm{e}^{8}(2)$ & $3.56 \mathrm{e}^{8}(4)$ & $2.61 \mathrm{e}^{4}(1)$ \\
$M A E$ & $4.8 \mathrm{e}^{-5}(2)$ & $4.9 \mathrm{e}^{-5}(3)$ & $4.7 \mathrm{e}^{-5}(1)$ & $6.0 \mathrm{e}^{-4}(5)$ & $6.0 \mathrm{e}^{-4}(5)$ & $5.7 \mathrm{e}^{-5}(4)$ \\
\hline
\end{tabular}

A remarkable observation from Table 6 is the consistency between the three econometric distance measures $\left(K L I C_{(B S)}, N_{\text {new }}\right.$ and $\left.W_{\text {new }}\right)$ in the relative ordering of the different models. This observation demonstrates the strength of the new measures of distance between data and model VCMs that we use here. However, the informal/naive measure, $M A E$, generates quite a different

\footnotetext{
${ }^{11}$ Interest rate series are H-P filtered but not logged.

12 The figures in parentheses in the Table represent relative ordering of the different models in terms of the relevant distance measure.
} 
ordering of the candidate models, indicating substantial benefits to formal probabilistic ordering of models in studies of macroeconomic DSGE models. Below, we discuss the important findings of our moment-based model selection exercise.

Across all models and policy specifications, the cash-in-advance model in conjunction with a money growth rule yields the lowest Kullback-Leibler distance as well as the lowest test statistics for the modified Nagao and Ledoit-Wolf tests. As far as these distance measures are concerned it is the specification whose filtered VCM comes closes to filtered VCM of the data. On the other hand, the mean absolute error distance measure is lowest for the CIA model under the interest rate rule. Our distance measures also suggest that it is difficult to distinguish between alternative ways of introducing money when monetary policy is characterized by an interest rate feedback rule. This suggests that any effects of an inflation tax associated with the shopping time and cash-in-advance models may be rather minimal. When monetary policy is modelled via a money growth rule, however, there are large differences between models, with only the CIA model yielding satisfactory results.

\section{Using distance measures for calibration}

In the preceding analysis, we calibrated our models using a common set of parameter values, except for the adjustment cost parameter, which we chose so as to match the relative volatility of investment generated by the model to its value in the data. An alternative approach is to choose the adjustment cost parameter to minimize one of our distance measures. Tables 7 and 8 show distance measures and generated moments when the adjustment cost parameter is chosen to minimize the KLIC (bootstrap) distance measure.

Table 7: Test Statistics: Choosing adjustment cost parameter to minimise KLIC (bootstrap) distance measure

\begin{tabular}{lcccccc}
\hline \hline & \multicolumn{3}{c}{ Interest rate rules } & \multicolumn{3}{c}{ Money growth rules } \\
& MIU & ST & CIA & MIU & ST & CIA \\
& & & & & & \\
$K L I C(B S)$ & 1230 & 1355 & 782 & 379 & 710 & 22.28 \\
$N_{\text {new }}$ & $5.74 \mathrm{e}^{8}$ & $6.34 \mathrm{e}^{8}$ & $1.97 \mathrm{e}^{8}$ & $4.06 \mathrm{e}^{7}$ & $1.68 \mathrm{e}^{8}$ & $2.24 \mathrm{e}^{4}$ \\
$W_{\text {new }}$ & $5.70 \mathrm{e}^{8}$ & $6.30 \mathrm{e}^{8}$ & $1.96 \mathrm{e}^{8}$ & $4.03 \mathrm{e}^{7}$ & $1.67 \mathrm{e}^{8}$ & $2.22 \mathrm{e}^{4}$ \\
\hline
\end{tabular}

Based on our distance measures the ordering of our models remains roughly unchanged. Just as in our previous calibration strategy, there is still very little difference between all three models under the interest rate rule. Under the money growth rule, as well as overall, the cash-in-advance specification emerges as the model that comes closest to the data.

Table 8 shows a selection of second moments for the alternative calibration. Comparing the results from table 5 with those from table 8 suggests that even though the alternative calibration comes closer to the data, none of the appar- 
Table 8: Data and model economies: 1960:1 - 2003:4 adjustment cost parameter chosen to minimise the KLIC (bootstrap) distance measure

\begin{tabular}{lccccccc}
\hline \hline & Data & \multicolumn{3}{c}{ Interest rate rules } & \multicolumn{3}{c}{ Money growth rules } \\
& & MIU & ST & CIA & MIU & ST & CIA \\
$\epsilon_{K}$ & & -5.22 & -6.45 & -4.35 & -2.59 & -3.01 & -50.42 \\
$\sigma_{\mathrm{GDP}}$ & 1.57 & 1.42 & 1.54 & 1.41 & 2.42 & 2.50 & 1.39 \\
$\sigma_{\text {variable }} \sigma_{\mathrm{GDP}}$ & & & & & & & \\
$\quad$ Consumption & 0.79 & 0.57 & 0.59 & 0.60 & 0.69 & 0.66 & 0.39 \\
$\quad$ Investment & 3.19 & 2.75 & 2.65 & 2.64 & 2.23 & 2.38 & 3.62 \\
$\quad$ Hours & 0.92 & 0.77 & 0.83 & 0.81 & 1.36 & 1.41 & 1.17 \\
$\quad$ Real wage & 0.48 & 0.59 & 0.53 & 0.78 & 0.53 & 0.43 & 0.68 \\
$\quad$ Inflation & 0.31 & 0.30 & 0.27 & 0.30 & 0.42 & 0.37 & 0.51 \\
$\quad$ Wage inflation & 0.33 & 0.07 & 0.06 & 0.06 & 0.23 & 0.22 & 0.31 \\
Interest rate & 0.25 & 0.08 & 0.07 & 0.08 & 0.01 & 0.01 & 0.30 \\
Corr(variable, GDP $)$ & & & & & & & \\
$\quad$ Consumption & 0.86 & 0.99 & 0.99 & 0.99 & 0.99 & 0.99 & 0.94 \\
$\quad$ Investment & 0.89 & 0.99 & 0.99 & 0.99 & 0.99 & 0.99 & 0.99 \\
$\quad$ Hours & 0.88 & 0.65 & 0.72 & 0.64 & 0.89 & 0.90 & 0.64 \\
$\quad$ Real wage & 0.26 & 0.73 & 0.68 & 0.73 & -0.09 & -0.16 & 0.37 \\
$\quad$ Inflation & 0.37 & -0.22 & -0.18 & -0.22 & 0.68 & 0.70 & 0.29 \\
$\quad$ Wage inflation & 0.18 & 0.61 & 0.66 & 0.60 & 0.92 & 0.93 & 0.64 \\
$\quad$ Policy rate & 0.36 & -0.88 & -0.88 & -0.88 & 0.49 & 0.35 & 0.54 \\
Autocorrelations & & & & & & & \\
$\quad$ GDP & 0.85 & 0.73 & 0.71 & 0.73 & 0.64 & 0.63 & 0.88 \\
$\quad$ Consumption & 0.87 & 0.75 & 0.71 & 0.74 & 0.65 & 0.65 & 0.80 \\
$\quad$ Investment & 0.90 & 0.72 & 0.71 & 0.72 & 0.63 & 0.61 & 0.90 \\
$\quad$ Inflation & 0.30 & 0.27 & 0.25 & 0.27 & 0.40 & 0.39 & 0.50 \\
& & & & & & & \\
\hline
\end{tabular}

ent inadequacies of our model appear to be redressed by alternative calibration of the adjustment cost parameter. The models under an interest rate rule still generate counter-cyclical inflation and policy rates and the MIU and ST models under the money growth rule still generate a counter-cyclical real wage. Where the last two mentioned models improve is in the volatility of GDP which is reduced, resulting in a lower relative volatility of investment, but a higher relative volatility of consumption.

\section{Demand shocks?}

Given that the models under an interest rule still generate both a countercyclical inflation rate and a counter-cyclical policy rate, it has been suggested that perhaps what is missing in this literature is a demand shock that moves interest rates and inflation in the same direction as output. To examine this 
proposition, we follow Canzoneri et al. (2004) and add a demand shock in the form of a shock to government spending. A shock to government spending enters the model via the economy-wide resource constraint: ${ }^{13}$

$$
Y_{t}=C_{t}+x_{t}+G_{t}
$$

An alternative way of modelling a demand shock is via a preference shock that changes the marginal utility of consumption. It can be shown that essentially the two approaches are the same. In both cases the shock enters the consumption Euler equation through the marginal utility of consumption. ${ }^{14}$ Given that shocks to government spending are easier to measure, we proceed following Canzoneri et al. We take Canzoneri et al.'s estimated shock process, which is estimated over almost the same time period as the rest of our estimated shocks. Canzoneri et al. find that the government spending shock has a persistence of 0.973 and a standard deviation of 0.01 . We assume that the government spending shock is not correlated with either productivity or monetary shocks. Just as in Canzoneri et al., we assume a share of government spending in GDP of $20 \%$. We choose $\epsilon_{K}$ to match the volatility of investment relative to that of GDP, to be consistent with our results of table 5 .

Table 9 suggests that adding government spending shocks does not remedy the counter-cyclical inflation and interest rate of all three models under the interest rate rule specification. Nolan and Thoenissen (2005) suggest that inflation becomes pro-cyclical when we drop the assumption of sticky wages, or at least when wages are less sticky than prices. Table 10 allows us to answer the question whether adding a demand side shock helps the overall fit of the models. Test statistics followed by a $(*)$ indicate where a model's fit is improved by the inclusion of a demand shock. It is straightforward to compare the fit of the baseline models (Table 6 ) with those of the models that include a government spending shock using the KLIC distance measure. Based on this measure we find some improvement for the models under a money growth rule, but the models closed with an interest rate rule are actually taken further away from the data by adding our government spending shock. We can compare the modified Nagao and Ledoit-Wolf test statistic by adjusting for the degrees of freedom (df). The test statistics in table 6 all have a df of 16 , whereas those of table 10 have a df of 21. Doing this conversion shows that the MIU and the ST models closed with a money growth rule improve, whereas all other specifications are taken further away from the data. The MAE statistics can also be compared directly between tables 6 and 10. Again we find somewhat different results. Here the ST and CIA under the interest rate rule as well as the MIU and ST under the money growth rule improved.

\footnotetext{
${ }^{13}$ Government spending is assumed to be neither utility nor productivity enhancing.

${ }^{14}$ If we model the shock as a 'preference shifter', we get the following linearised expression for the marginal utility of consumption: $-\sigma\left[\frac{y}{c} y_{t}-\frac{x}{c} x_{t}\right]+p(1-\sigma) \hat{\zeta}_{t}=\hat{\mu}_{t}$, where $\hat{\zeta}$ is the preference shock and $p$ is a parameter. When the shock is applied to the resource constraint we can write the marginal utility of consumption as: $-\sigma\left[\frac{y}{c} y_{t}-\frac{x}{c} x_{t}\right]+\sigma \frac{g}{c} \hat{g}_{t}=\hat{\mu}_{t}$
} 
Table 9: Data and model economies: 1960:1 - 2003:4 Monetary, Productivity and government spending shocks

\begin{tabular}{lccccccc}
\hline \hline & Data & \multicolumn{3}{c}{ Interest rate rules } & \multicolumn{3}{c}{ Money growth rules } \\
& & MIU & ST & CIA & MIU & ST & CIA \\
$\epsilon_{K}$ & & -6.8 & -10.21 & -6.23 & -4.97 & -5.02 & -7.55 \\
$\sigma_{\text {GDP }}$ & 1.57 & 1.41 & 1.58 & 1.42 & 2.73 & 2.69 & 1.34 \\
$\sigma_{\text {variable }} \sigma_{\mathrm{GDP}}$ & & & & & & & \\
$\quad$ Consumption & 0.79 & 0.63 & 0.63 & 0.64 & 0.62 & 0.62 & 0.67 \\
$\quad$ Investment & 3.19 & 3.19 & 3.19 & 3.19 & 3.19 & 3.19 & 3.19 \\
$\quad$ Hours & 0.92 & 0.82 & 0.89 & 0.84 & 1.39 & 1.43 & 1.18 \\
$\quad$ Real wage & 0.48 & 0.61 & 0.53 & 0.61 & 0.39 & 0.41 & 0.72 \\
Inflation & 0.31 & 0.30 & 0.27 & 0.30 & 0.33 & 0.35 & 0.54 \\
$\quad$ Wage inflation & 0.33 & 0.07 & 0.06 & 0.06 & 0.21 & 0.21 & 0.37 \\
Interest rate & 0.25 & 0.08 & 0.07 & 0.08 & 0.01 & 0.01 & 0.33 \\
Corr(variable, GDP $)$ & & & & & & & \\
$\quad$ Consumption & 0.86 & 0.93 & 0.95 & 0.94 & 0.98 & 0.97 & 0.94 \\
$\quad$ Investment & 0.89 & 0.99 & 0.99 & 0.99 & 0.99 & 0.99 & 0.99 \\
$\quad$ Hours & 0.88 & 0.63 & 0.73 & 0.64 & 0.91 & 0.91 & 0.61 \\
$\quad$ Real wage & 0.26 & 0.70 & 0.64 & 0.69 & -0.18 & -0.22 & 0.39 \\
$\quad$ Inflation & 0.37 & -0.19 & -0.15 & -0.20 & 0.71 & 0.72 & 0.32 \\
$\quad$ Wage inflation & 0.18 & 0.62 & 0.66 & 0.60 & 0.94 & 0.94 & 0.67 \\
$\quad$ Policy rate & 0.36 & -0.88 & -0.89 & -0.89 & 0.60 & 0.43 & 0.50 \\
Autocorrelations & & & & & & & \\
$\quad$ GDP & 0.85 & 0.73 & 0.70 & 0.72 & 0.62 & 0.61 & 0.87 \\
Consumption & 0.87 & 0.75 & 0.72 & 0.75 & 0.65 & 0.65 & 0.82 \\
$\quad$ Investment & 0.90 & 0.71 & 0.69 & 0.71 & 0.60 & 0.59 & 0.89 \\
$\quad$ Inflation & 0.30 & 0.26 & 0.24 & 0.26 & 0.36 & 0.36 & 0.51 \\
& & & & & & & \\
\hline
\end{tabular}

\subsection{Pro-cyclical policy rate in the CIA model under a money growth rule}

A key finding of our analysis is the consistently good performance of the cashin-advance model when combined with a money growth rule. Our econometric analysis suggests that this model best matches the data. One feature that might account for the model's success is the fact that, unlike competing models, it yields both pro-cyclical inflation and policy rate.

This subsection attempts to account for the positive correlation between the policy rate and GDP. Our analysis of impulse response functions suggests that the main difference between the models closed via a money growth rule and those models closed by an interest rate feedback rule lies in the response to a monetary policy shock. If we model monetary policy via a money growth rule, both output and the nominal interest rate rise in response to a positive shock to the growth rate of the money supply, whereas output rises in response to 
Table 10: Test Statistics: Productivity, monetary and demand shock

\begin{tabular}{lcccccc}
\hline \hline & \multicolumn{3}{c}{ Interest rate rules } & \multicolumn{3}{c}{ Money growth rules } \\
& MIU & ST & CIA & MIU & ST & CIA \\
& & & & & & \\
$K L I C(B S)$ & 1654 & 1680 & 988 & $538^{*}$ & $893^{*}$ & $22.13^{*}$ \\
$N_{\text {new }}$ & $9.49 \mathrm{e}^{8}$ & $9.89 \mathrm{e}^{8}$ & $3.31 \mathrm{e}^{8}$ & $9.91 \mathrm{e}^{7^{*}}$ & $2.77 \mathrm{e}^{8 *}$ & $3.96 \mathrm{e}^{4}$ \\
$W_{\text {new }}$ & $9.43 \mathrm{e}^{8}$ & $9.83 \mathrm{e}^{8}$ & $3.29 \mathrm{e}^{8}$ & $9.86 \mathrm{e}^{7^{*}}$ & $2.76 \mathrm{e}^{8 *}$ & $3.92 \mathrm{e}^{4}$ \\
$M A E$ & $6.01 \mathrm{e}^{-5}$ & $4.11 \mathrm{e}^{-5 *}$ & $5.90 \mathrm{e}^{-7 *}$ & $3.88 \mathrm{e}^{-4 *}$ & $3.87 \mathrm{e}^{-4 *}$ & $5.74^{-5}$ \\
\hline
\end{tabular}

a decrease in the policy rate in the models closed by an interest rate feedback rule.

Danthine and Kurmann (2004) point out that the CIA model (closed with a money growth rule) fails to a generate a liquidity effect whereby the nominal interest rates falls following a rise in the real money supply, and suggest that it is related to the counter-factual way in which monetary policy is modelled. Unlike in most VAR studies, inflation in our model does not have a 'hump' shaped profile in response to a monetary shock. If we compare the response of the nominal interest rate to a monetary shock (Figure 3), we find that the CIA model generates a much larger increase in the nominal interest rate than either the MIU or the ST models, which suggests an alternative explanation linked to the cash-in-advance constraint. Indeed, in a cash-in-advance model an increase in the money supply immediately raises both consumption and investment, as the constraint on these two components of GDP is relaxed. In this way, a shock to the growth rate of the money supply acts like the demand shock, which some authors, including Canzoneri et al. (2004) have suggested is missing from the standard NNS model.

\section{Conclusions}

In this paper, we ask the questions: Does it matter how we model the role of money in the New Neoclassical Synthesis (NNS) model characterized by monopolistic competition, price and wage stickiness as well as endogenous capital accumulation? And does it matter how we model monetary policy? It is well understood that the NNS model when closed by an interest rate feedback rule generates a counter-cyclical policy and inflation rate, whereas the data suggest that the two series are in fact pro-cyclical. One aim of our paper is to investigate if this shortcoming of the NNS model is related to the way we model the role of money and how we model monetary policy. Our findings suggest that the counter-cyclical policy and inflation rates are common to the moneyin-the-utility, the shopping time as well as the cash-in-advance versions of our basic NNS model as long as monetary policy is modelled via an interest rate feedback rule. On the other hand, when monetary policy is modelled via a money growth rate, we find that our NNS model generates pro-cyclical policy 
and inflation rates. We also observe that in response to an unexpected increase in the money growth rate the cash-in-advance model generates 'hump' shaped impulse responses for output, consumption and investment.

To answer the question as to which of the models and specifications comes closest to the data, we employ new econometric methods that allow us to compare and rank nested and non-nested models against each other and the data. The tests compare the variance-covariance matrix of the model economy with that generated by the data. Our results suggest a clear and consistent ranking of models. The cash-in-advance model in conjunction with the money growth rule matches the data moments most closely, whereas the money-in-the-utility model closed by an estimated interest rate feedback rule is one of the models furthest removed from the data.

Finally, we examine if adding a demand shock can improve the fit of the models and resolve the counter-cyclical policy and inflation rate issue encountered in some of our specifications. We find that adding a demand shock does not resolve the counter-cyclicality issue and only improves the overall fit of the money growth rule models. 


\section{References}

[1] Bartlett, M.S. (1954). 'A note on multiplying factors for various chi-squared approximations', Journal of the Royal Statistical Society, Series B, 16, pages 296-8.

[2] Bhattacharjee, A. and Chadha, J.S. (2005) 'Selection of DSGE models based on covariance matrix when the number of shocks is small'. Mimeo.

[3] Bhimasankaram, P. and Sengupta, D. (1991). 'Testing for the mean vector of a multivariate normal distribution with a possibly singular dispersion matrix and related results'. Statistics and Probability Letters vol. 11, pages 473-8.

[4] Bils, M. and Klenow, P. (2004). 'Some evidence on the importance of sticky prices', Journal of Political Economy, October, pages 947-87

[5] Calvo, G.A. (1983). 'Staggered prices in a utility maximising framework', Journal of Monetary Economics, vol. 12, pages 383-98.

[6] Canova, F. and Ortega, E. (2000). 'Testing calibrated general equilibrium models'. In Mariano, R., Shuermann, T. and Weeks, M. (eds.) Inference using Simulation Techniques, Cambridge University Press.

[7] Canzoneri, M.B., Cumby, R. E. and Diba, B. T. (2004). 'The cost of nominal inertia in NNS models', Mimeo.

[8] Chari, V.V. and Kehoe, P.J. (1999). 'Optimal fiscal and monetary policy', NBER Working paper 6891.

[9] Chari, V.V., Kehoe, P.J. and McGrattan, E. (2000). 'Sticky price models of the business cycle: Can the contract multiplier solve the persistence problem?', Econometrica, 68(5), pages 1151-79.

[10] Danthine, J.P and Kurmann, A. (2004). 'Fair wages in a New Keynesian model of the business cycle', Review of Economic Dynamics, vol. 7, pages $107-42$.

[11] Diebold, F.X., Ohanian, L.E. and Berkowitz, J. (1998). 'Dynamic equilibrium economies: A framework for comparing models and data', Review of Economic Studies, vol. 65, pages 433-51.

[12] Erceg, C.J., Henderson, D.W. and Levin, A.T. (2000). 'Optimal monetary policy with staggered wage and price contracts', Journal of Monetary Economics, vol. 46(2), pages 381-413.

[13] Gavin, W.T. and Kydland, F.E. (1999). 'Endogenous money supply and the business cycle', Review of Economic Dynamics, vol. 2, pages 347-69.

[14] Ireland, P.N. (2004). 'A method for taking models to the data', Journal of Economic Dynamics and Control, vol. 28, pages 1205-26. 
[15] King, R. and Watson, M. (1998). 'The solution of singular linear difference systems under rational expectations', International Economic Review, vol. 39, no 4, pages 1015-26.

[16] King, R. and Watson, M. (2000). 'System reduction and solution algorithms for singular linear difference systems under rational expectations', Computational Economics, vol 20, pages 57-86.

[17] Kollmann, R. (2005). 'Macroeconomic effects of nominal exchange rate regimes: new insights into the role of price dynamics', Journal of International Money and Finance, vol. 24, pages 275-92.

[18] Ledoit, O. and Wolf, M. (2002). 'Some hypothesis tests for the covariance matrix when the dimension is large compared to the sample size'. Annals of Statistics vol. 30, pages 1081-102.

[19] Nagao, H. (1973). 'On some test criteria for covariance matrix', The Annals of Statistics, 1, pages 700-9.

[20] Nolan, C. and Thoenissen, C. (2005). Labour markets and firm-specific capital in new Keynesian general equilibrium models', Mimeo.

[21] Muirhead, R.J. (1982). Aspects of Multivariate Statistical Theory. Wiley: New York.

[22] Srivastava, M.S. (2003). 'Singular Wishart and multivariate Beta distributions', The Annals of Statistics, 31(5), pages 1537-60.

[23] Uhlig, H. (1994). 'On singular Wishart and singular multivariate Beta distributions'. The Annals of Statistics vol. 22, pages 395-405.

[24] Wang, P.F. and Wen, Yi. (2005). 'Another look at sticky prices and output persistence', Journal of Economic Dynamics and Control, forthcoming.

[25] Watson, M. (1993). 'Measures of fit for calibrated models'. Journal of Political Economy vol. 101, pages 1011-1041.

[26] Woodford, M. (2003). Interest and Prices, Foundations of a theory of monetary policy. Princeton University Press. 


\section{A The data}

Our data are of quarterly frequency and come from two main sources: the US Department of Commerce: Bureau of Economic Analysis (BEA) and US Department of Labor: Bureau of Labor Statistics (BLS) and span the sample period 1960:1 to 2003:4.

1. GDP refered to in tables 5, 8 and 9 is real GDP per capita from BEA's NIPA table 7.1. 'Selected Per Capita Product and Income Series in Current and Chained Dollars', seasonally adjusted. The series was logged and H-P filtered.

2. Consumption referred to in tables 5, 8 and 9 is total consumption expenditures deflated by the relevant GDP deflator, both from BEA's NIPA tables 2.3.5 and 1.1.9.

3. Investment referred to in tables 5, 8 and 9 is real fixed investment per capita from BEA's NIPA table 5.3.3. Real Private Fixed Investment by Type. Population is from NIPA table 7.1.

4. Hours referred to in tables 5, 8 and 9 is per capita hours worked in nonfarm businesses, from BLS, series code PRS85006033. Population is from NIPA table 7.1.

5. Real wage referred to in tables 5,8 and 9 is real hourly compensation from BLS, series code PRS85006153.

6. Inflation referred to in tables 5,8 and 9 is defined as $\pi=\log \left(P_{t} / P_{t-1}\right)$, where $P$ is consumer price index for all urban consumers, from BLS series CUSR0000SA0.

7. Wage inflation referred to in tables 5,8 and 9 is constructed using nominal hourly compensation from BLS, series code PRS85006103 $W_{t}$. $\omega=$ $\log \left(W_{t} / W_{t-1}\right)$.

8. Interest rate referred to in tables 5,8 and 9 is the effective US federal funds rate.

9. Potential output used to construct the output gap measure in our estimated Taylor rule is taken from the Congressional Budget Office measure of potential output.

10. The Solow residual is constructed as follows:

$$
A_{t}=y n f b_{t}-s_{k} \log \left(K_{t}\right)-\left(1-s_{k}\right) \log \left(N_{t}\right)
$$

where $y n f b$ is the log of real GDP in the non-farm business sector, series PRS85006043 from BLS. $N_{t}$ is aggregate hours worked, as above, but not deflated by the population. $K$ is real non-residential fixed assets, constructed following Stock and Watson (1999). 

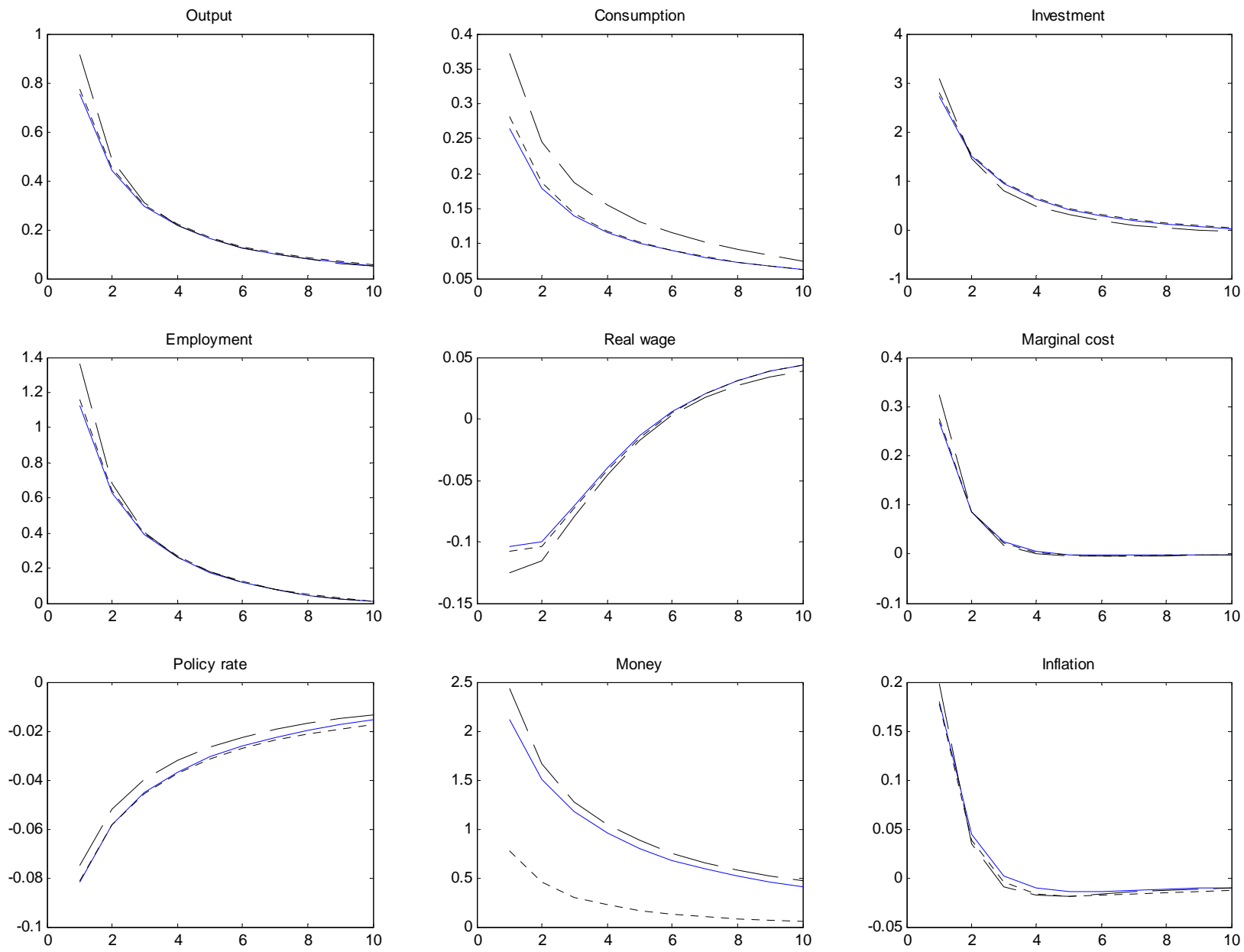

Figure 1: Impulse response functions with respect to a $\mathbf{- 1 \%}$ interest rate shock for the MIU model (solid), Shopping time model (dashed) and CIA model (dotted). 

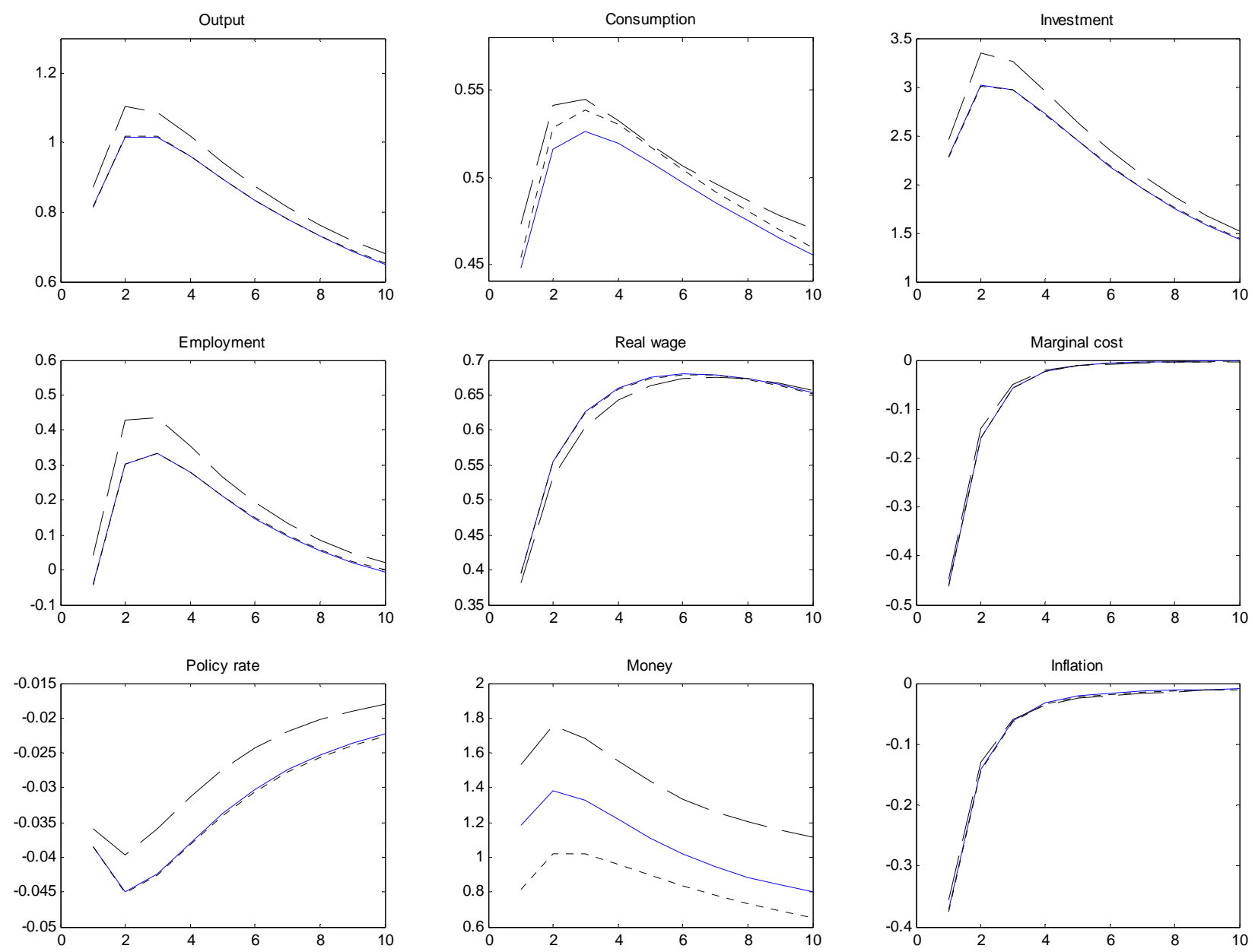

Figure 2: Impulse response functions with respect to a $1 \%$ technology shock for MIU model (solid), Shopping time model (dashed) and CIA model (dotted) under an interest rate rule 

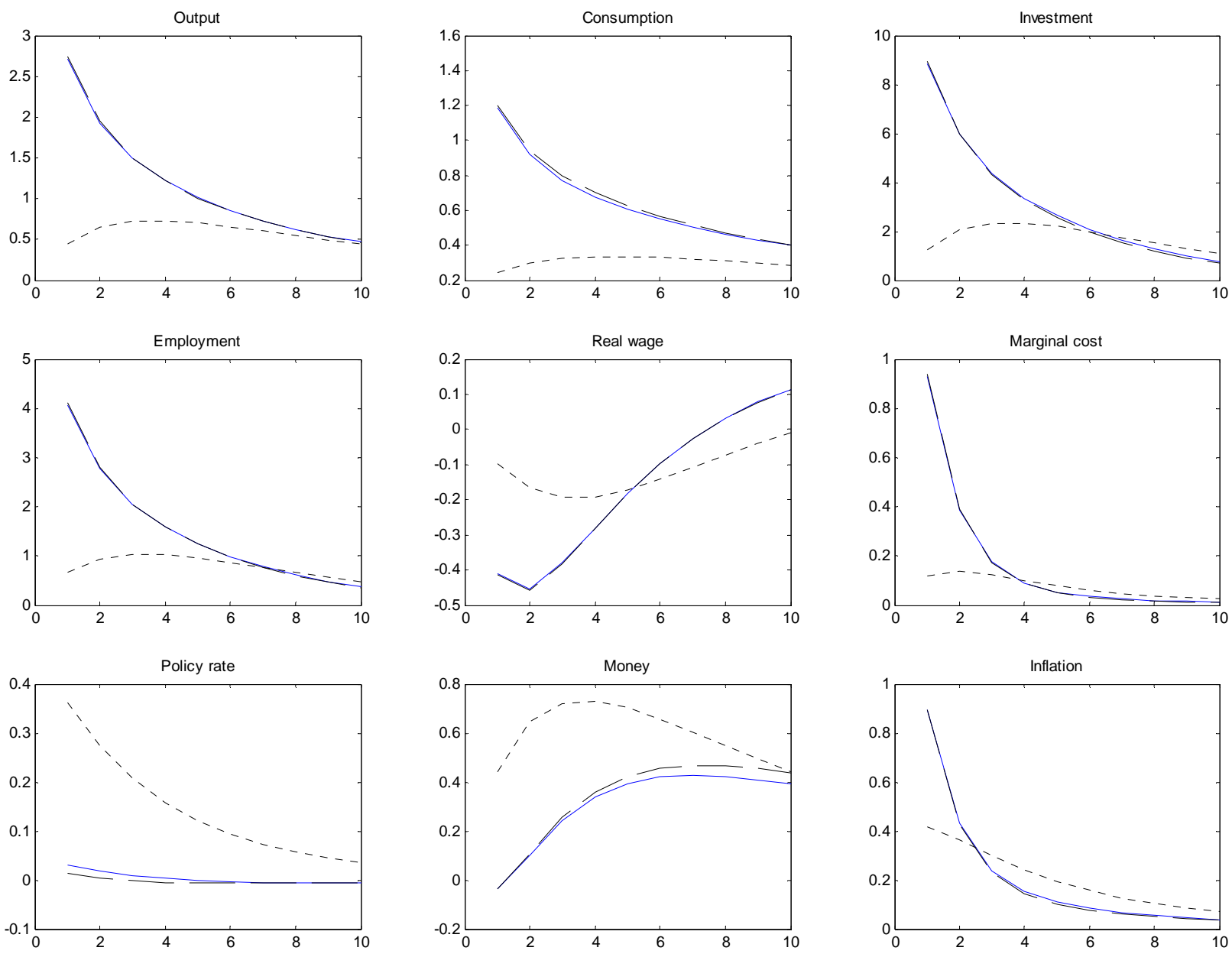

Figure 3: Impulse response function with respect to a $1 \%$ money growth rate shock for the MIU (solid), Shopping Time (dashed) and CIA model (dotted). 

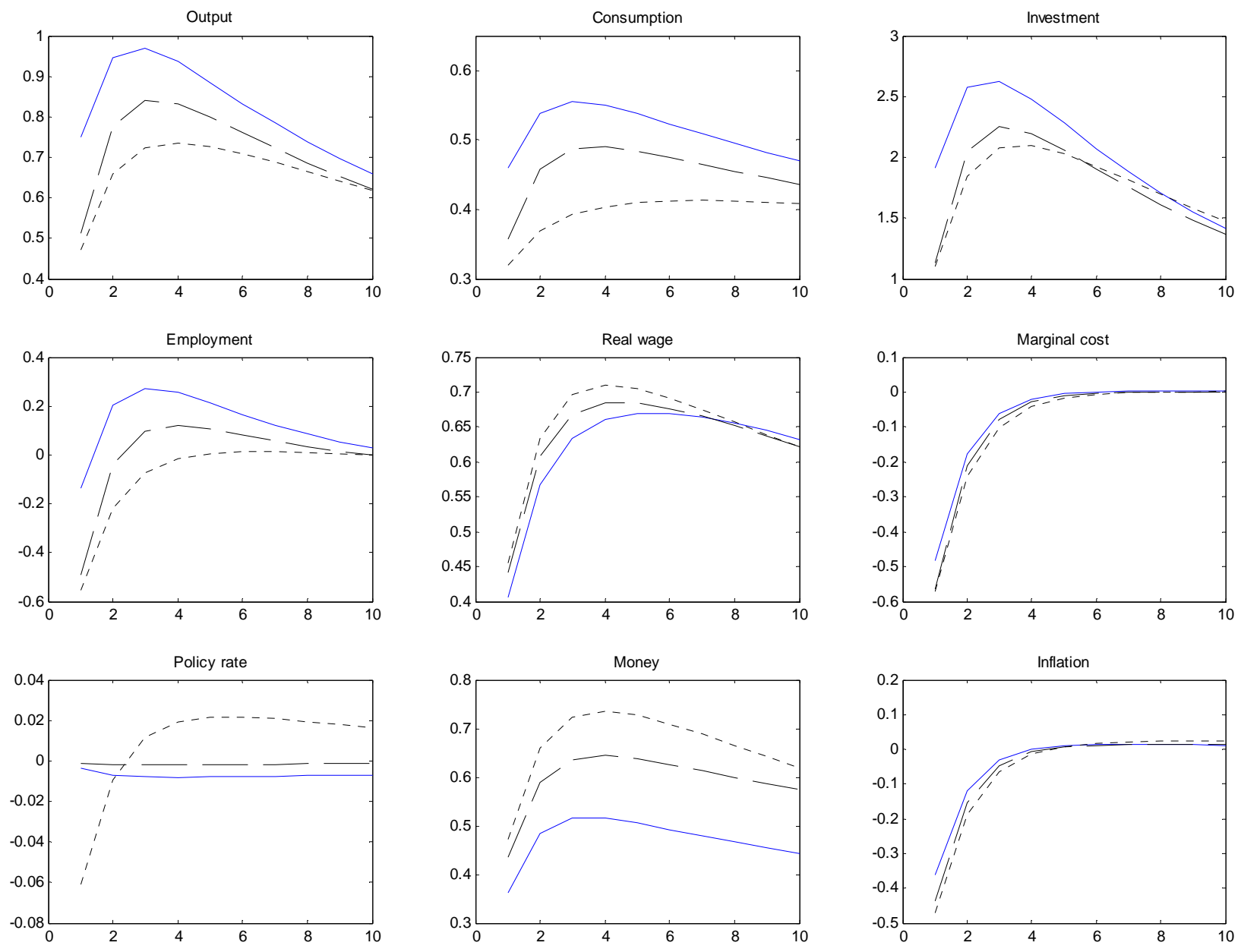

Figure 4: Impulse response functions with respect to a 1\% technology shock for MIU model (solid), Shopping time model (dashed) and CIA model (dotted) under a money growth rule. 